OPEN ACCESS

Edited by:

James Guy Castley,

Griffith University, Australia

Reviewed by:

Nakul Chettri,

International Centre for Integrated Mountain Development, Nepal Gopalasamy Reuben Clements, Universiti Malaysia Terengganu, Malaysia

*Correspondence: Bilal Habib

bilalhabib1@gmail.com bh@wii.gov.in

Specialty section:

This article was submitted to Conservation

a section of the journal

Frontiers in Ecology and Evolution

Received: 30 May 2016 Accepted: 03 November 2016 Published: 22 November 2016

Citation:

Habib B, Rajvanshi A, Mathur VB and Saxena A (2016) Corridors at Crossroads: Linear

Development-Induced Ecological Triage As a Conservation Opportunity. Front. Ecol. Evol. 4:132 doi: 10.3389/fevo.2016.00132

\section{Corridors at Crossroads: Linear Development-Induced Ecological Triage As a Conservation Opportunity}

\author{
Bilal Habib *, Asha Rajvanshi, Vinod B. Mathur and Akanksha Saxena \\ Wildlife Institute of India, Dehradun, India
}

The transportation infrastructure of a nation forms the backbone of its economic growth and social development, and, as a developing country, India is no exception. However, with imperatives to improve connectivity for economic and social growth, ecological costs are often at stake. Roads, old and new, cut through protected forests and connecting habitats, resulting in a plethora of ecological effects. These may include the severing of natural corridors thereby compromising the role of landscapes as conservation units especially for landscape-dependent wild animal species. Consequent loss of biodiversity and ecosystems and decline in innumerable ecosystem services emanating from these natural reserves are other serious impacts. As India aspires for better, modern roads, the ecological concerns regarding many road upgradation projects have recently been the cause of disputes between the transportation sector and the conservation community. Delayed consideration of ecological concerns into linear development project planning leads to inadequate appropriation of funds needed for mitigating impacts of such developments. It is in these circumstances that the question of prioritizing areas and strategies for mitigation given limited mitigation funds arises. We examine the different facets to the debate of triage vis-à-vis conservation, development and mitigation planning in the transportation sector in a developing country context. We suggest that it is important and possible to secure investment toward conservation in areas outside the purview of legal protection through project mitigation costs and other mechanisms. We also make suggestions to avoid the "laissez-faire" approach to linear development projects that is prevalent in India.

Keywords: roads, corridors, conservation, triage, sustainable development, mitigation

\section{INTRODUCTION}

Much of India's economic growth in the past two decades has been driven by infrastructure development, prominent among them being development in the transportation sector. This can be attributed to reorientation of government spending toward public infrastructure (Ministry of Finance, 2016), including road-based transportation infrastructure. India today has the second largest road network in the world (ca. 5.2 million km), after the United States of America ${ }^{1}$. For a developing country like India, the importance of an efficient transportation system cannot be

${ }^{1}$ National Highways Authority of India (http://www.nhai.org) 
understated: roads facilitate social well-being and economic development (Elisseeff, 1998). The manufacturing centers, commercial and cultural centers, that are the nuclei of development, are already connected via a well-built network of over 24,000 km of roads ${ }^{1}$. Many rural areas in India are now being connected to better civic amenities and economic opportunities via roads networks. With an annual economic growth pegged at 7-7.5 percent for the fiscal year 2016-17 (Ministry of Finance, 2016), the scale of infrastructure development is also set to increase.

Concurrent with India's high-paced development is the country's unique global position in terms of its biodiversity. Being one of the 17 megadiverse countries of the world (with $7-8 \%$ of the world's species, of which $12.6 \%$ of mammals, $4.5 \%$ of birds, $45.8 \%$ of reptiles, $55.8 \%$ of amphibians and $33 \%$ of Indian plants ${ }^{2}$ are endemic), four of the world's biodiversity hotspots (Myers et al., 2000) are also located in India- Western Ghats and Sri Lanka (Western Ghats), Himalaya (Indian Himalaya), Indo-Burma (parts of North east India) and Sundaland (Nicobar Islands) (Pande and Arora, 2014). The vast biological wealth is comparable to the diversity of geographical features (plateaus, mountains, plains) and habitats and ecosystems (forests, grasslands, wetlands, deserts).

India is also home to $57 \%$ of the world's tiger population (Jhala et al., 2015; WWF, 2016). The tiger, being a keystone species, regulates prey populations thus reducing trophic cascades. In India, the protection and management of forested ecosystems has thus been envisaged through its conservation as a flagship species (Leader-Williams and Dublin, 2000) through a network of tiger reserves in landscapes across the country. The populations in these tiger reserves act as metapopulations, across which genetic exchange is vital for longterm persistence of the national animal. Securing the habitats and movement pathways of the tiger by extension equates to conserving all other species that share these forests (Roberge and Angelstam, 2004) and the invaluable ecosystem services provisioned by these forests. Habitat connectivity for tigers in Indian landscapes has been evaluated and mapped through GIS-based landscape permeability models (Qureshi et al., 2014; Mondal et al., 2016), and genetic analysis in combination with landscape permeability models (Joshi et al., 2013; Yumnam et al., 2014), generating structural corridors. These corridor maps are used to identify corridors that may be threatened by road construction/expansion. Securing these corridors is vital for maintaining landscape-level gene flow (Yumnam et al., 2014) and is an essential, and critical component of conservation of such species (Bennet, 1990). Similar corridors have been identified for connecting and conserving elephant populations (Menon et al., 2005).

However, a great part of these corridors lies outside the protected area (PA) network and under different land ownership tenures. It is in such areas that the challenge of building roads and nature conservation become most daunting. Many high-traffic highways crisscross the few remaining forested landscapes of the country and cause an array of short- and long-term ecological

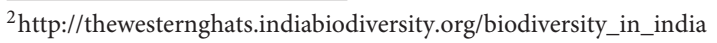

impacts. Intrusion of roads in natural areas and activities associated with road building and operation adversely impact native biodiversity through multiple pathways (Jalkotzy et al., 1997; Kumara et al., 2000; Forman et al., 2003; Donaldson and Bennett, 2004). Road-related disturbances create a filter to animal movement across their habitats on either side of the roads and, in the long-run, can cause populations of animals to disappear from habitats that have become isolated and fragmented by roads (Riley et al., 2006). In India, roads have affected daily and seasonal movement pathways of elephants, hoolock gibbons, one-horned rhinoceros and other mammals (Choudhury, 1987; Joshi and Singh, 2007; Gubbi et al., 2012; Krishna et al., 2013; Wildlife Institute of India, 2014). In the Central Indian Landscape alone, an important tiger conservation landscape (TCL), tiger corridors are bisected by at least $4302 \mathrm{~km}$ of national and state highways, upgradation of many of which are currently underway.

The objectives of road infrastructure development often conflict with efforts to maintain undisturbed and well-connected swathes of forested areas across landscapes. Development agencies see the merit of promoting upgradation of highway infrastructure in keeping with development aspirations of the country. However conservation groups advocate avoiding further development in sensitive habitats/wildlife corridors, opting for alternative alignments, adopting best possible mitigation measures for maintaining habitat connectivity and reducing animal mortality (where development cannot be avoided), and better and early integration of conservation issues into project inception, planning and design. In reality, however, development priorities take center-stage and several issues confound or hinder any cooperation between conservation and development proponents.

The lack of strategic/landscape-level planning in India (Saxena et al., 2016) to enable consideration of conservation objectives in transportation development policies, plans and programs results in a lack of or delayed participation of conservation proponents in the decision-making process. Such projects are therefore constrained in terms of allocation of resources for exploring options of avoidance, minimization, rehabilitation and offsetting. Considering these constraints, delayed intervention through litigation from conservation proponents after necessary permissions have been obtained by the developers leaves few options for mitigation planning and ensuing mitigation planning has to be prioritized considering limitations in the form of funding and political will to formulate and implement such plans.

This paper explores different facets to the debate on the "triage-like" situation that arises as a result of competing development and conservation objectives in the context of road upgradation projects in India using a prominent recent example. The case exemplifies the present status of delayed mainstreaming of conservation concerns into infrastructure development projects in the country. This delay in assessment of the anticipated threats to a vital wildlife corridor from the soon-to-be upgraded road translated into limited options to mitigate these threats. The ensuing prioritization exercise regarding choice of alignment, locations and specifications of mitigation measures made in light of the conservation 
importance of corridors, severity of threats, cost and possibility of positive conservation outcomes through mitigation, based on ecologically-informed alignment and mitigation alternatives have also been discussed. It concludes that implementation of mitigation measures in road upgradation projects in India can offer better avenues for promoting conservation in areas outside the purview of legal protection than status quo. To avoid future stand-offs resulting from the prevalent piece-meal approach to development, we suggest strategic environmental assessments and landscape-scale inter-sectoral planning for the road development sector to better include conservation concerns into development plans. We also suggest science-based prioritization exercises to delineate "no-go" zones by weighing costs and benefits of developing some lands and conserving others, and at the same time identifying areas where development is inevitable but conservation action can be mainstreamed into development projects.

\section{USING TRIAGE TO ENABLE CONJUNCTION OF HUMAN AND WILDLIFE PASSAGE}

Ecological triage is an informed prioritization of species to conserve, given their ecological role and chances of averting extinction through investment in conservation actions, after which funds for conserving these species are allocated accordingly (Hobbs and Kristjanson, 2003). However, triage of species must now move toward triage of habitats (Hudson, 2011), since pouring money to save a single species when its habitat is not preserved is moot (Shepard, 2011). Saving tigers and their habitats in India follows the same approach. However, given different threats to corridors outside the purview of protection, and limited funds for mitigation and conservation sourced from developers, it becomes imminent to prioritize areas where these funds would give the most positive conservation outcomes. Given duly established criteria for prioritizing landscapes for conservation are in place, the criteria to be given the highest weighting should be the magnitude of threats to the habitat.

Although development in the road sector in India is imminent and undeniably essential, it is the upgradation of arterial hightraffic highways passing through ecologically rich and sensitive areas that has to be dealt in light of factors justifying the need for expansion, increasing trends in traffic volume and the conservation importance commanded by the areas being traversed by roads. This was best exemplified in the case of upgradation of the National Highway (NH) 7, an arterial highway that connects major cities in Central India to the northern and southern parts of India. Upgradation work on the highway was initiated under Phase III of the National Highways Development Plan (NHDP). After upgradation work was completed in the non-forested sections of the road stretches, upgradation work was halted in a forested stretch that cut across the Pench-Kanha corridor, a critical tiger corridor in Central India for which clearances were required as conservation and forest authorities were not included in the project planning stages. The 2-lane configuration of $\mathrm{NH} 7$ had not incorporated animal passageways as part of its original design, barring the natural drainage structures, which were used by wildlife in the absence of other suitable structures (Rajvanshi et al., 2013). Sandwiched between the upgraded segments (Figure 1), the forested 2-laned segment received greater number of vehicles per unit time than the 4laned segments, thereby posing a threat of creating a barrier for animal movement across the corridor.

An alternative route via Chhindwara, Maharashtra, involving an additional length of $70 \mathrm{~km}$ ( $55 \%$ increase in distance) was suggested by a conservation organization. This alignment posed a threat to the connectivity of the Pench-Satpura-Melghat corridor which is vital for connecting six tiger reserves in the landscape. Opting for this alignment would also require re-alignment of $122 \mathrm{~km}$ of an existing highway (17\% of which was in the hills), diversion of 163 ha of forest land and felling of 81,500 trees (Wildlife Institute of India, 2012).

The imminent threat to the Pench-Kanha corridor because of increase in and funneling of traffic on $\mathrm{NH} 7$ was greater given its high use (daily traffic volume on $\mathrm{NH}$ 7 increased from 3048 to 6151 in three years Wildlife Institute of India, 2012; Habib et al., 2015). This meant that abandoning upgradation plans on this stretch would hinder movement in the corridor further. So long as mitigation measures conducive to animal movement were incorporated in the initial alignment, the possibility of recovery of this corridor was thought to be greater. Considering implications for wildlife conservation and future projections of road development and traffic growth, it was thus considered prudent to allow upgradation of the existing alignment (Habib et al., 2015).

\section{PRIORITIZING MITIGATION ACTIONS, STRUCTURES AND TARGETS}

Choosing the target species/group for mitigation planning requires prioritization of the goals of mitigation that could be aimed at maintaining viable populations of select species across the landscape, reducing the risk to human lives due to animalvehicle collisions (van der Grift et al., 2013), or at reducing road-related animal mortality, and vice-versa. This would however depend on local conditions, development objectives and conservation priorities that need to be set out clearly at project inception stages.

In case of $\mathrm{NH} \mathrm{7,} \mathrm{it} \mathrm{was} \mathrm{considered} \mathrm{best} \mathrm{to} \mathrm{focus} \mathrm{on}$ the entire suite of locally available species (30 mammals22 of which belong to Schedule I and II of the Wildlife (Protection) Act, 1972) to achieve the desired goals. Moreover, since it is not always feasible to address the concerns of each species in a landscape, measures that would address the concerns of most animals in the landscape were considered. The predominant criteria was, however, to provide connectivity for the flagship species, for which we relied on corridor maps created for tigers in the landscape. Thus, it was proposed to build flyovers across all forested corridors by an appraisal of the initial project plan (Wildlife Institute of India, 2012). The objective was to provide structures large enough to offer natural 


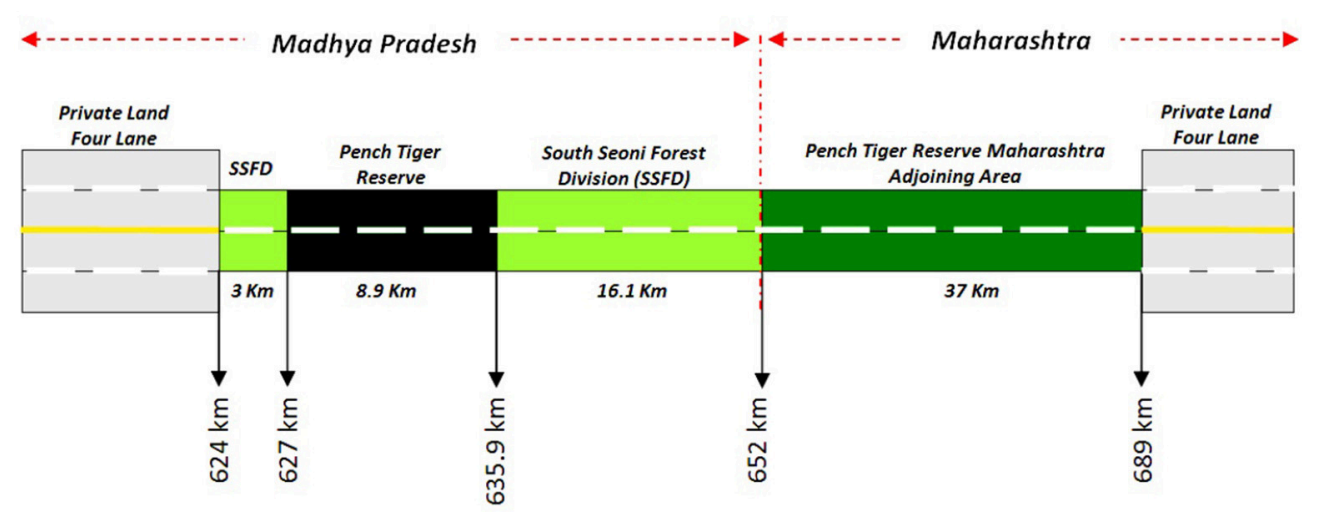

FIGURE 1 | Location of 2-laned segment of NH 7 between upgraded 4-laned segments causing a funneling of traffic.

passage to animals in the soon-to-be upgraded sections of the highway.

We achieved this by demarcating animal crossing zones based on sign surveys and then prioritizing locations of crossing structures based on the intensity of use by animals, and presence of villages and other ancillary development along the road stretch. In places where animal signs were found adjacent to villages and farmlands with weak connectivity to adjacent habitat patches, crossing structures were not suggested considering the possibility of conflict with humans. Some crossing zones were found to overlap natural drainage and in these places it was suggested to enhance existing drainage structures to facilitate use by animals, resulting in a multi-use structure.

\section{USING TRIAGE TO CONNECT PEOPLE AND HABITATS: CONCLUSIONS AND WAY FORWARD}

The average size of PAs in India is ca 220 sq. $\mathrm{km}^{3}$, and is not enough to sustain long-term viable wildlife populations, particularly of landscape-dependent species such as elephant and tiger (Woodroffe and Ginsberg, 1998; Yumnam et al., 2014). These areas thus need to remain connected through a network of forested tracts outside the PA network, which often fall under different land ownership tenures. Existing and new roads in these lands inevitably lead to conflict with the objectives of maintaining connectivity among protected areas. Such roads, when upgraded, also present us with an opportunity to implement mitigation measures that offset the development impacts and those of the existing infrastructure. The internalization of mitigation costs incurred by developers into India's economic development can prove to be minimal in the long-term (Hudson, 2011).

Given the lack of strategic land-use planning in India and late consideration of conservation concerns into project planning, mitigation funds are not always adequate. Therefore

${ }^{3}$ http://www.wiienvis.nic.in/Database/Protected_Area_854.aspx science-based prioritization exercises of areas that are threatened by development and have a positive chance of recovery via investments in mitigation need to be outlined. Landscape conservation plans could also be used to guide the application of mitigation planning of development plans by overlapping development plans (present and future) with conservation objectives and align development and mitigation plans accordingly. Such exercises would also help delineate "no-go" zones for linear developments (Kiesecker et al., 2009). Hobbs and Kristjanson (2003) outlined a grid-like prioritization system that has been modified from emergency health-care for the "treatment" of landscapes. This approach helps assign appropriate levels and types of care to the landscapes considering relative level of threat and probability of recovery, factors critical for setting priority (Joseph et al., 2009). Prioritizing which corridors or habitats to save in no way means abandoning areas that are difficult to save or those with development interests; it merely allocates limited mitigation funding strategically to achieve conservation goals through effective mitigation planning (Bottrill et al., 2009).

New mechanisms for funneling development funds for conservation outside the PA system are currently being formulated in India. For example, under a new program, the MoEFCC is working on new guidelines to incentivize proponents to carry out afforestation and purchase and transfer land within recognized corridors as part of the compensatory afforestation program.

Strategic or landscape-level inter-sectoral assessments and land-use planning exercises could also help avoid issues that ensue as a consequence of a piece-meal approach to development, the prevalent practice in India today. This would also ensure that instead of keeping conservationists at the periphery in dealing with large development interests (Klages, 2010), they are engaged early in planning stages to evolve scientifically sound approaches in favor of the protection of ecosystems and ecosystem services within the mitigation hierarchy of such development plans. This strategy would both influence and be influenced by the allocation of 
funds dedicated to avoiding and ameliorating development impacts to natural landscapes, and the business and political willingness to do so. There is also a need to initiate dialogue on science-based prioritization criteria suited to the conservation and development needs of India among conservation scientists which would then translate into prioritization in planning.

As conservationists, we cannot stop progress but we can shape it (Rosner, 2013). Identifying opportunities for positive conservation action through unavoidable development imperatives can help bridge the gap between our desire to conserve and our ability to conserve.

\section{REFERENCES}

Bennet, A. F. (1990). Habitat corridors and the conservation of small mammals in a fragmented forest environment. Landsc. Ecol. 4, 109-122. doi: $10.1007 / \mathrm{BF} 00132855$

Bottrill, M. C., Joseph, L. N., Carwardine, J., Bode, M., Cook, C., Game, E. T., et al. (2009). Finite conservation funds means triage is unavoidable. Trends Ecol. Evol. (Amst). 24, 183-184. doi: 10.1016/j.tree.2008.11.007

Choudhury, A. (1987). Railway threat to Kaziranga. Oryx 21, 160-163. doi: $10.1017 /$ S0030605300026892

Donaldson, A., and Bennett, A. (2004). Ecological Effects of Roads - Implications for the Internal Fragmentation of Australian Parks and Reserves. Melbourne, VIC: Parks Victoria.

Elisseeff, V. (ed.). (1998). The Silk Roads: Highways of Culture and Commerce. Paris: UNESCO.

Forman, R. T. T., Sperling, D., Bissonette, J. A., Clevenger, A. P., Chutshall, C. D., Dale, V. H., et al. (2003). Road Ecology. Science and Solutions. Washington, DC: Island Press.

Gubbi, S., Poornesha, H. C., and Madhusudan, M. D. (2012). Impact of vehicular traffic on the use of highway edges by large mammals in a South Indian Wildlife Reserve. Curr. Sci. 102, 1047-1051

Habib, B., Saxena, A., Mondal, I., Rajvanshi, A., Mathur, V. B., and Negi, H. S. (2015). Proposed Mitigation Measures for Maintaining Habitat Contiguity and Reducing Wild Animal Mortality on NH 6 \& 7 in the Central Indian Landscape. Technical Report, Wildlife Institute of India, Dehradun and National Tiger Conservation Authority, Govt. of India, New Delhi.

Hobbs, R. J., and Kristjanson, L. J. (2003). Triage: how do we prioritize health care for landscapes? Ecol. Manage. Restoration. 4, 39-45. doi: 10.1046/j.1442-8903.4.s.5.x

Hudson, B. (2011). Conservation Triage- "Should Conservationists Allow Some Species to Die Out?”. Available online at: http://lawprofessors.typepad.com/ environmental_law/2011/05/conservation-triage-should-conservationistsallow-some-species-to-die-out.html (Accessed August 12, 2016).

Jalkotzy, M. G., Ross, P. I., and Nasserden, M. D. (1997). The Effects of Linear Developments on Wildlife: A Review of Selected Scientific Literature. Report: 1-354. Calgary, Prep. for Canadian Association of Petroleum Producers. Arc Wildlife Services Ltd.

Jhala, Y. V., Qureshi, Q., and Gopal, R., (eds.). (2015). The Status of Tigers in India 2014. National Tiger Conservation Authority. New Delhi, Dehradun: The Wildlife Institute of India.

Joseph, L. N., Maloney, R. F., and Possingham, H. P. (2009). Optimal allocation of resources among threatened species: a project prioritization protocol. Conserv. Biol. 23, 328-338. doi: 10.1111/j.1523-1739.2008.01124.x

Joshi, A., Vaidyanathan, S., Mondol. S., Edgaonkar, A., and Ramakrishnan, U. (2013). Connectivity of tiger (Panthera tigris) populations in the human-influenced forest mosaic of Central India. PLoS ONE. 8:e77980. doi: 10.1371/journal.pone.0077980

Joshi, R., and Singh, R. (2007). Asian elephants are losing their seasonal traditional movement tracks: a decade of study in and around the Rajaji National Park, India. Gajah 27, 15-26.

\section{AUTHOR CONTRIBUTIONS}

$\mathrm{BH}, \mathrm{AS}, \mathrm{AR}$, and VM: Designed the paper, drafted and revised the paper, and approved the final version of the manuscript before submission. All authors contributed equally to this paper.

\section{ACKNOWLEDGMENTS}

We are thankful to the National Tiger Conservation Authority (NTCA), India, for funding our research. We are also thankful to the Maharashtra and Madhya Pradesh State Forest Departments for logistic support during field work.

Kiesecker, J. M., Copeland, H., Pocewicz, A., and McKenney, B. (2009) Development by design: blending landscape-level planning with the mitigation hierarchy. Front. Ecol. Environ. 8, 261-266. doi: 10.1890/090005

Klages, A. (2010). Triage: conserving primates and competing interests. Univ. West. Ont. J. Anthropol. 18, 22-34. Available online at: http://ir.lib.uwo.ca/ totem/vol18/iss1/12

Krishna, C. M., Kumar, A., Ray, P. C., Sarma, K., Devi, A., and Khan, M. L. (2013). Impact of road widening on wildlife in Namdapha National Park, Arunachal Pradesh, India: a conservation issue. Asian J. Conserv. Biol. 2, 76-78.

Kumara, H. N., Sharma, A. K., Kumar, A., and Singh, M. (2000). Roadkills of wild fauna in Indira Gandhi Wildlife Sanctuary, Western Ghats, India: implications for management. Biosph. Conserv. 3, 41-47.

Leader-Williams, N., and Dublin, H. T. (2000). "Charismatic megafauna as 'flagship' species," in Has the Panda Had Its day? Future Priorities for the Conservation of Mammal Diversity, eds A. Entwistle and N. Dunstone (Cambridge: Cambridge University Press), 53-81.

Menon, V., Tiwari, S. K., Easa, P. S., and Sukumar, R., (eds.). (2005). Right of Passage: Elephant corridors of India. Conservation Reference Series No. 3. New Delhi: Wildlife Trust of India.

Ministry of Finance, (2016). Economic Outlook, Prospects and Policy Challenges. In Economic Survey 2015-16. Ministry of Finance, Government of India. Available online at: http://indiabudget.nic.in/

Mondal, I., Habib, B., Nigam, P., and Talukdar, G. (2016). Tiger Corridors of Eastern Vdarbha Landscape. Report number: TR 2016/009. Wildlife Institute of India, Dehradun and National Tiger Conservation Authority, New Delhi.

Myers, N., Mittermeier, R. A., Mittermeier, C. G., da Fonseca, G. A. B., and Kent, J. (2000). Biodiversity hotspots for conservation priorities. Nature 403, 853-858. doi: $10.1038 / 35002501$

Pande, K. H., and Arora, S., (eds.). (2014). India's Fifth National Report to the Convention Of Biological Diversity (2014). Ministry of Environment and Forests, Govt. of India.

Qureshi, Q., Saini, S., Basu, P., Gopal, R., Raza, R., and Jhala, Y. (2014). Connecting Tiger Populations for Long-term Conservation. Dehradun: National Tiger Conservation Authority \& Wildlife Institute of India.

Rajvanshi, A., Mathur, V. B., and Pragatheesh, A. (2013). Ecological Effects of Road Through Sensitive Habitats: Implications for Wildlife Conservation. Dehradun: Wildlife Institute of India.

Riley, S. P. D., Pollinger, J. P., Sauvajot, R. M., York, E. C., Bromley, C., Fuller, T. K., et al. (2006). A southern California freeway is a physical and social barrier to gene flow in carnivores. Mol. Ecol. 15, 1733-1741. doi: 10.1111/j.1365-294X.2006.02907.x

Roberge, J.-M., and Angelstam, P. (2004). Usefulness of the umbrella species concept as a conservation tool. Conserv. Biol. 18, 76-85. doi: 10.1111/j.1523-1739.2004.00450.x

Rosner, H. (2013). Is Conservation Extinct? Available online at: http://ensia.com/features/is-conservation-extinct/ (Accessed May 19, 2016).

Saxena, A., Rajvanshi, A., and Mathur, V. B. (2016). Progressive trends in the uptake of SEA in South Asia. J. Environ. Assess. Policy Manage. 18, 2. doi: $10.1142 /$ S1464333216500186 
Shepard, W. (2011). Ecological Triage is Unavoidable and Nothing New for Conservationists. Available online at: http://www.vagabondjourney.com/ ecological-triage-is-unavoidable-and-nothing-new-for-conservationist/ (Accessed August 12, 2016).

van der Grift, E. A., van der Ree, R., Fahrig, L., Findlay, S., Houlahan, J., Jaeger, J. A. G., et al. (2013). Evaluating the effectiveness of road mitigation measures. Biodivers. Conserv. 22, 425-448. doi: 10.1007/s10531-012-0421-0

Wildlife Institute of India (2012). Revised Proposal for 4-Laning of National Highway 7: A Review. Dehradun: Wildlife Institute of India.

Wildlife Institute of India (2014). Review of the Proposal: Submitted by the Government of Assam in Compliance of the Order of the Hon'ble National Green Tribunal, to Suggest Mitigation Measures in the Interest of Wildlife Conservation with Respect to National Highway 37. Dehradun: Wildlife Institute of India.

WWF (2016). Global Wild Tiger Population Document. Background Document. WWF Tx2 Tiger Initiative. Available online at: http://globaltigerinitiative. org/site/wp-content/uploads/2016/04/Background-Document-Wild-TigerStatus-2016.pdf
Woodroffe, R., and Ginsberg, J. R. (1998). Edge effects and the extinction of populations inside protected areas. Science 280, 2126-2128. doi: 10.1126/science.280.5372.2126

Yumnam, B., Jhala, Y. V., Qureshi, Q., Maldonado, J. E., Gopal, R., Saini, S., et al. (2014). Prioritising tiger conservation through landscape genetics and Habitat Linkages. PLOS ONE 9:e111207. doi: 10.1371/journal.pone. 0111207

Conflict of Interest Statement: The authors declare that the research was conducted in the absence of any commercial or financial relationships that could be construed as a potential conflict of interest.

Copyright (C) 2016 Habib, Rajvanshi, Mathur and Saxena. This is an open-access article distributed under the terms of the Creative Commons Attribution License (CC $B Y)$. The use, distribution or reproduction in other forums is permitted, provided the original author(s) or licensor are credited and that the original publication in this journal is cited, in accordance with accepted academic practice. No use, distribution or reproduction is permitted which does not comply with these terms. 